\title{
Clinical Reasoning Education at US Medical Schools: Results from a National Survey of Internal Medicine Clerkship Directors
}

\author{
Joseph Rencic, $M D^{7}$, Robert L. Trowbridge Jr, MD², Mark Fagan, MD ${ }^{3}$, Karen Szauter, $M D^{4}$, and \\ Steven Durning, MD, $P h D^{5}$
}

${ }^{1}$ Tufts Medical Center, Boston, MA, USA; ${ }^{2}$ Maine Medical Center, Portland, ME, USA; ${ }^{3}$ Rhode Island Hospital, Providence, RI, USA; ${ }^{4}$ University of Texas Medical Branch, Galveston, TX, USA; 5 Uniformed Services University of the Health Sciences, Bethesda, MD, USA.

BACKGROUND: Recent reports, including the Institute of Medicine's Improving Diagnosis in Health Care, highlight the pervasiveness and underappreciated harm of diagnostic error, and recommend enhancing health care professional education in diagnostic reasoning. However, little is known about clinical reasoning curricula at US medical schools.

OBJECTIVE: To describe clinical reasoning curricula at US medical schools and to determine the attitudes of internal medicine clerkship directors toward teaching of clinical reasoning.

DESIGN: Cross-sectional multicenter study.

PARTICIPANTS: US institutional members of the Clerkship Directors in Internal Medicine (CDIM).

MAIN MEASURES: Examined responses to a survey that was emailed in May 2015 to CDIM institutional representatives, who reported on their medical school's clinical reasoning curriculum.

KEY RESULTS: The response rate was 74\% (91/123). Most respondents reported that a structured curriculum in clinical reasoning should be taught in all phases of medical education, including the preclinical years (64/ $85 ; 75 \%)$, clinical clerkships $(76 / 87 ; 87 \%)$, and the fourth year $(75 / 88 ; 85 \%)$, and that more curricular time should be devoted to the topic. Respondents indicated that most students enter the clerkship with only poor $(25 / 85 ; 29 \%)$ to fair $(47 / 85 ; 55 \%)$ knowledge of key clinical reasoning concepts. Most institutions (52/91; 57\%) surveyed lacked sessions dedicated to these topics. Lack of curricular time (59/67, 88\%) and faculty expertise in teaching these concepts $(53 / 76,69 \%)$ were identified as barriers.

CONCLUSIONS: Internal medicine clerkship directors believe that clinical reasoning should be taught throughout the 4 years of medical school, with the greatest emphasis in the clinical years. However, only a minority reported having teaching sessions devoted to clinical reasoning, citing a lack of curricular time and faculty expertise as the largest barriers. Our findings suggest that additional institutional and national resources should be dedicated to developing clinical reasoning curricula to improve diagnostic accuracy and reduce diagnostic error.

Electronic supplementary material The online version of this article (doi:10.1007/s11606-017-4159-y) contains supplementary material, which is available to authorized users.

Received November 3, 2016

Revised March 30, 2017

Accepted August 7, 2017

Published online August 24, 2017
J Gen Intern Med 32(11):1242-6

DOI: $10.1007 / \mathrm{s} 11606-017-4159-\mathrm{y}$

(c) Society of General Internal Medicine 2017

\section{INTRODUCTION}

Despite significant advances in patient safety since the seminal 1999 Institute of Medicine report, To Err is Human, ${ }^{1}$ the health care system continues to grapple with an excess of medical errors. ${ }^{2,3}$ Diagnostic errors are implicated in a huge proportion of cases, affecting millions of individuals and causing an estimated 40,000-80,000 deaths each year in the United States alone. ${ }^{4}$ There are many causes of diagnostic error, but cognitive factors (e.g., faulty medical knowledge, data gathering and synthesis) resulting in diagnostic reasoning failures rank among the most important. ${ }^{5,6}$ As medical school training provides the foundation for the development of clinical reasoning skills, undergraduate medical education can potentially play a critical role in improving diagnostic accuracy and mitigating diagnostic error. This recognition, along with the current national spotlight on reducing diagnostic errors, naturally prompts an examination of how clinical reasoning is taught within medical schools.

Traditionally, medical schools begin clinical reasoning instruction in the preclinical years through a series of "doctoring" courses focused on topics such as patient interviewing, the physical examination, and pathophysiology. However, these courses typically do not explicitly address the clinical reasoning process in a structured fashion. Interactions with patients and exposure to resident and attending role models during the clinical years thus serve as the major means of fostering clinical reasoning capabilities in learners. This unstandardized process depends on the teaching skills of role models. Stated another way, clinical reasoning ability is often "caught" by learners as opposed to being explicitly "taught" to them.

Recent advances in cognitive psychology pertaining to diagnostic reasoning have provided theoretical insights for developing a framework for clinical reasoning curricula. As a result, reports of clinical reasoning courses have emerged in the medical education literature, ${ }^{7-11}$ yet data regarding the national state of clinical reasoning curricula in medical schools are lacking. Such data are needed to enable educators and 
policymakers to propose optimal solutions at the medical school level to help mitigate medical errors. To address this gap in the literature, we developed a set of questions, administered through a national survey of designated institutional representatives of the Clerkship Directors of Internal Medicine (CDIM), to investigate the content and format of clinical reasoning teaching in US medical schools. Additionally, we sought to determine clerkship directors' attitudes toward clinical reasoning curricula and to identify barriers to the adoption of such curricula.

\section{METHODS}

\section{Design}

We used a cross-sectional survey methodology to obtain data about current clinical reasoning curricula and clerkship director attitudes regarding these curricula at US medical schools.

\section{Setting and Participants}

We used data from the 2015 CDIM annual survey of US medical schools. The designated CDIM institutional representatives at 123 allopathic medical schools were contacted via email and provided with a web-based questionnaire. Nonresponders received up to three follow-up requests by email and telephone.

\section{Survey Development and Data Collection}

The 2015 CDIM survey was developed from member submissions in response to an open invitation extended in the fall of 2014 for research proposals addressing important topics and questions regarding medical student education. The CDIM Survey and Scholarship Committee reviewed all proposals and selected five topics based on relevance to the current educational climate. The section on clinical reasoning education was one of five components of the 2015 survey. Other sections of the survey, which comprised a total of 126 questions, explored longitudinal integrated clerkships, milestones and Core Entrustable Professional Activities for Entering Residency (CEPAER), direct observation of learners, and duties of clerkship directors. Another section of the survey collected demographic information including the respondent's academic rank, age, sex, and primary role in internal medicine education.

Three of the authors (JR, RT, SJD), who recently conducted a literature review and served as editors on a textbook regarding clinical reasoning teaching, ${ }^{12}$ developed the initial draft of the survey questions pertaining to clinical reasoning. The questions were reviewed and revised by members of the Survey and Scholarship Committee in close collaboration with the authors. Once the survey questions were edited, a draft of the entire survey was reviewed and revised by the CDIM Council. The survey items were also pilot-tested with members of the survey committee and the CDIM Council, followed by final revisions. The final survey was emailed using SurveyMonkey ${ }^{\circledR}$ on May 20, 2015, to the designated CDIM representative at each member institution. These representatives are typically current internal medicine clerkship directors, or serve in a role that has direct oversight of the internal medicine clerkship. The list of designated institutional representatives is updated annually, and every effort is made to ensure that the survey is sent to the person at each institution with detailed knowledge of the internal medicine clerkship. All data were anonymized. The survey closed on August 17, 2015. The study was approved by the institutional review board at the Washington DC VA Medical Center.

The topics and terms of the clinical reasoning questions were chosen based on a literature review and on the expertise of the author group. Eight questions with multiple sub-items on clinical reasoning education were developed, and included free text as well as rating scales, including modified Likert scales (online Appendix 1). Questions were focused on foundational topics of clinical reasoning, including the underlying theory (dual process, illness scripts), reasoning strategies (pre-test probability, thresholds to test and treat, heuristics, likelihood ratios, decision analysis), and common causes of diagnostic error (premature closure, cognitive bias). Premature closure and cognitive bias were both selected, because they are considered common causes of error and are familiar concepts to medical educators. The questions focused on the respondents' perceptions of three aspects of these topics: current and ideal curricula, importance, and student knowledge.

\section{Statistical Analysis}

The results were analyzed in a de-identified, confidential format. Institutional respondents were used as the unit of analysis. Unanswered items were not included in the analysis. Descriptive statistics were performed on all responses and calculated using a standard statistical software program (SPSS version 12; SPSS Inc., Chicago, Illinois).

\section{RESULTS}

Ninety-five of 123 (77\%) institutional representatives completed the CDIM survey. The institutional geographic distribution represented every region of the country, with 59 (62\%) public and $36(38 \%)$ private medical schools responding. The majority of respondents identified their role (role reported by $n=90$ ) as clerkship director, co-clerkship director, or associate clerkship director $(n=84)$. The other six comprised five vice chairs for education and one assistant dean. The number of responses by sex were almost equal $(n=87)$, with $43(49 \%)$ women and $44(51 \%)$ men. The academic rank distribution $(n=91)$ was as follows: 43 associate professors $(47 \%), 22$ professors (24\%), 25 assistant professors (28\%), and one instructor $(1.0 \%)$. The majority of respondents $(n=60)$ were between the ages of 35 and 55 years. Four respondents did not complete any portion of the clinical reasoning education 
section and were excluded from our analysis, resulting in a $74 \%$ response rate ( $n=91$ respondents).

The majority of respondents felt that a structured curriculum in clinical reasoning should be taught in all phases of medical education, including the preclinical years (3.9, SD 0.7), clinical clerkships (4.4, SD 0.7), and the fourth year (4.3, SD 0.7, Table 1). Most reported that students had a fair or poor understanding of all clinical reasoning concepts presented, with very few $(<5 \%)$ answering that students had an excellent understanding of these concepts (Table 2). Eighty percent of respondents used small group case discussions to teach clinical reasoning, with $96 \%$ agreeing that it should be taught in this way. Clinical reasoning teaching most commonly occurred in attending rounds (76\%) and morning report (66\%). Nearly all respondents felt that these were the two best venues for teaching it (96 and 91\%, respectively; Table 3).

Respondents endorsed the importance of teaching clinical reasoning concepts in the clerkship years, rating all potential topics as at least moderately important (Table 4). The most important topics were premature closure (3.9, SD 1.0), pre-test probability estimation (3.8, SD 1.0), thresholds to test and treat (3.8, SD 1.0), and cognitive bias (3.7, SD 1.0). Formal decision analysis (2.60, SD 1.0), the use of likelihood ratios (3.2, SD 0.9), and dual process theory (3.3, SD 0.9 ) were considered the least important. Despite the expressed importance of teaching clinical reasoning concepts in the clinical years, most sites did not have sessions specifically devoted to these topics. Only pre-test probability estimation was specifically taught in a majority of sites (54.8\%), with the other topics ranging from 16.7 to $48.8 \%$.

The time dedicated to clinical reasoning in the internal medicine clerkships ranged from 0 to $32 \mathrm{~h}$, with an average of $6.4 \mathrm{~h}$ over the course of the clerkship. Most clerkship directors $(67 \%)$ believed that more time should be dedicated to clinical reasoning teaching in the clerkship. Respondents identified a lack of curricular time (87\%) and a lack of faculty qualified to teach these concepts (70\%) as barriers. Few respondents $(16 \%)$ believed that the perception that clinical reasoning cannot be taught was a significant barrier.

\section{DISCUSSION}

These results from a national survey of important institutional educators provide the first empirical evidence regarding the content of, venues for, and barriers to clinical reasoning teaching in undergraduate medical education. Our North American medical school survey showed that the majority of CDIM institutional representatives felt that clinical reasoning should be taught in all phases of undergraduate medical education, which supports similar recommendations by authoritative bodies such as the Institute of Medicine ${ }^{2}$ and the Coalition to Improve Diagnosis. ${ }^{12}$

Respondents' reports that students with poor to fair knowledge of clinical reasoning receive an average of only $6.4 \mathrm{~h}$ of dedicated clinical reasoning teaching highlight the need for a specific emphasis on the development of clinical reasoning skills throughout the educational process. Our study supports the notion that learners may not be able to gain proficiency in clinical reasoning solely through patient interactions and exposure to role models. Although these modalities will always remain a cornerstone for the development of clinical reasoning abilities, our data suggest that this process should be nurtured and supported by specific curricular programs in all phases of medical education, and should be a specific and explicit goal of medical education.

Our survey attempted to address why medical schools are lagging in developing curricula dedicated to teaching clinical reasoning. Clerkship directors identified barriers to implementing additional instruction in clinical reasoning, including lack of curricular time and qualified faculty, with curricular time reported as the most significant barrier. The role of the physician in medicine has evolved dramatically over the past decade, and medical schools are now tasked with incorporating curricular initiatives centered on quality, patient safety, and systems engineering into an already dense educational agenda. ${ }^{13}$ Adding further instruction in clinical reasoning will undoubtedly be a challenge. Faculty expertise is also a significant issue. Although many clinical faculty may be experts in their fields, they may not be experts in teaching clinical reasoning. Most physicians can teach clinical reasoning by modeling the process and "thinking out loud," but certain topics may be more difficult for the traditional clinician educator who may have never explicitly learned about them. An additional problem is the lack of a gold standard for assessing clinical reasoning skills, making it difficult to determine the efficacy of educational interventions. Current research in clinical reasoning assessment may remedy this issue in the future. ${ }^{14}$

Most of the topics surveyed were considered important to teach, with estimation of pre-test probability, thresholds for testing and treatment, premature closure, and cognitive biases leading the list. This is a logical prioritization by clerkship

Table 1 Perceived Importance of the Timing of a Structured Curriculum to Explicitly Teach Concepts of Clinical Reasoning

\begin{tabular}{|c|c|c|c|c|c|c|}
\hline & $\begin{array}{l}\text { Extremely important } \\
\text { (5) }\end{array}$ & $\begin{array}{l}\text { Important } \\
\text { (4) }\end{array}$ & $\begin{array}{l}\text { Neutral } \\
\text { (3) }\end{array}$ & $\begin{array}{l}\text { Less important } \\
\text { (2) }\end{array}$ & $\begin{array}{l}\text { Unimportant } \\
\text { (1) }\end{array}$ & Mean (SD) \\
\hline In the preclinical years $(n=85)$ & $15(17.6)$ & $49(57.6)^{*}$ & $18(21.2)$ & $3(3.5)$ & $0(0.0)$ & $3.9(0.7)$ \\
\hline In the clinical clerkships $(n=87)$ & $41(47.1)$ & $35(40.2)$ & $10(11.5)$ & $0(0.0)$ & $1(1.1)$ & $4.4(0.7)$ \\
\hline In the fourth year $(n=88)$ & $41(46.6)$ & $34(38.6)$ & $11(12.5)$ & $1(1.1)$ & $1(1.1)$ & $4.3(0.7)$ \\
\hline
\end{tabular}

*Bold font denotes mode 
Table 2 Student Understanding of Clinical Reasoning Concepts upon Entering Clinical Clerkships

\begin{tabular}{|c|c|c|c|c|c|}
\hline & \multicolumn{4}{|c|}{ Degree of understanding } & \multirow[t]{2}{*}{ Mean (SD) } \\
\hline & $\begin{array}{l}\text { Excellent } \\
\text { (4) }\end{array}$ & $\begin{array}{l}\text { Good } \\
\text { (3) }\end{array}$ & $\begin{array}{l}\text { Fair } \\
\text { (2) }\end{array}$ & $\begin{array}{l}\text { Poor } \\
\text { (1) }\end{array}$ & \\
\hline Cognitive bias $(n=85)$ & $0(0.0)$ & $13(15.3)$ & $47(55.3)$ & $25(29.4)$ & $1.8(0.6)$ \\
\hline Dual processing $(n=83)$ & $1(1.2)$ & $5(6.0)$ & $40(48.2)$ & $37(44.6)$ & $1.6(0.6)$ \\
\hline Formal decision analytics $(n=85)$ & $1(1.2)$ & $13(15.3)$ & $37(43.5)$ & (34) 40.0 & $1.7(0.7)$ \\
\hline Heuristics $(n=83)$ & $0(0.0)$ & $12(14.5)$ & 43 (51.8) & $28(33.7)$ & $1.8(0.7)$ \\
\hline Illness scripts $(n=85)$ & $4(4.7)$ & $22(25.9)$ & 39 (45.9) & $20(23.5)$ & $2.1(0.8)$ \\
\hline Likelihood ratios $(n=84)$ & $4(4.8)$ & $26(31.0)$ & 40 (47.6) & $14(16.7)$ & $2.2(0.8)$ \\
\hline Pretest probabilities $(n=84)$ & $3(3.6)$ & $36(42.9)$ & $35(41.7)$ & $10(11.9)$ & $2.4(0.7)^{*}$ \\
\hline Premature closure $(n=83)$ & $3(3.6)$ & $13(15.7)$ & $44(53.0)$ & $23(27.7)$ & $1.9(0.8)$ \\
\hline Thresholds for testing and treatment $(n=83)$ & $2(2.4)$ & $14(16.9)$ & $43(51.8)$ & $24(28.9)$ & $1.9(0.7)$ \\
\hline
\end{tabular}

*Bold font denotes mode

directors, as the first two relate to differential diagnosis and decision making, two essential aspects of clinical reasoning. The assigned importance of premature closure and cognitive bias is also not surprising in light of the increased focus on the advantages and disadvantages of heuristics in both the popular press $^{15,16}$ and the medical literature. ${ }^{17,18}$ Cognitive error is the most common reason for diagnostic error, ${ }^{5}$ but continued research into how these types of errors may be reduced is needed before a robust evidence-based curriculum can be developed. ${ }^{17-21}$

Notably, respondents felt that clinical reasoning teaching should be increased in all venues mentioned. However, they felt least strongly about web-based learning. We speculate that this relates to concerns regarding the learning transfer of clinical reasoning skills from online educational activities to actual patient encounters. Learning transfer poses a challenge in all of these venues, although discussion and examination of actual patients in attending rounds and physical diagnosis sessions, respectively, would be expected to enhance it. Further study is needed to explore the issue of learning transfer in clinical reasoning teaching activities.

Limitations of our survey include a lack of information regarding institutional characteristics, which could result in non-response bias. However, our response rate suggests that the results include a broad spectrum of institutions in terms of size, location, and academic mission. Survey length

Table 3 Venues for Teaching Clinical Reasoning Topics in Internal Medicine Clerkships $(n=91)$

\begin{tabular}{|c|c|c|}
\hline & $\begin{array}{l}\text { Currently done, } \\
\text { no. }(\%)\end{array}$ & $\begin{array}{l}\text { Should be done, } \\
\text { no. }(\%)\end{array}$ \\
\hline Attending rounds & $69(75.8)$ & 87 (95.6) \\
\hline Morning report & $60(65.9)$ & $83(91.2)$ \\
\hline $\begin{array}{l}\text { Morbidity and mortality } \\
\text { conference }\end{array}$ & $37(40.7)$ & $66(72.5)$ \\
\hline Physical diagnosis rounds & $32(35.2)$ & $61(67.0)$ \\
\hline $\begin{array}{l}\text { Specific sessions devoted to } \\
\text { clinical reasoning }\end{array}$ & $39(42.9)$ & $64(70.3)$ \\
\hline Online programs & $17(18.7)$ & 34 (37.4) \\
\hline
\end{tabular}

constraints prevented the inclusion of terminology definitions, so some respondents may not have understood the meaning of the clinical reasoning terms. However, given the recent emphasis on clinical reasoning and diagnostic error in the medical education literature, we suspect that most experienced medical educators are familiar with these terms.

Other limitations include the exclusive focus on internal medicine, a specialty in which clinical reasoning is considered an essential skill. Therefore, our data likely provide a "bestcase scenario" estimation of clinical reasoning teaching and are not generalizable to other specialties. Furthermore, clerkship directors are typically more knowledgeable about the clinical than the preclinical years in undergraduate medical education, potentially limiting their ability to accurately describe the scope of instruction in clinical reasoning. However, the survey was distributed to designated institutional representatives who were expected to confer with the appropriate colleagues as needed to answer the survey items. Finally, clerkship directors were not asked to prioritize clinical reasoning relative to other curricular content, so the results may overestimate the importance of clinical reasoning teaching. However, most medical educators view clinical reasoning as an essential skill for the practicing clinician, and the fact that the Institute of Medicine views education on diagnostic error as an important priority suggests that clerkship directors are aligned with national thought leaders in their views.

These survey data suggest that students lack knowledge of key concepts in clinical reasoning and that a greater emphasis should be placed on clinical reasoning teaching in both the pre-clinical and clinical years. Currently, however, limited curricular time devoted to clinical reasoning and a lack of faculty expertise in this area are major barriers. Given the pressing need to improve diagnostic accuracy and reduce diagnostic error, we believe these data sound a clarion call for medical schools to re-prioritize resources toward building clinical reasoning curricula and developing faculty expertise. Further research to explore interventions for overcoming existing barriers is imperative. Ultimately, we believe that the medical education community should aim to develop a set of national standards and objectives regarding the teaching 
Table 4 Importance of Teaching Clinical Reasoning Topics and Current Coverage in Internal Medicine Clerkships

\begin{tabular}{|c|c|c|c|c|c|c|c|}
\hline & \multicolumn{5}{|c|}{ Degree of importance } & \multirow[t]{2}{*}{ Mean (SD) } & \multirow{2}{*}{$\begin{array}{l}\text { Currently covered } \\
(n=84), \text { no. }(\%)\end{array}$} \\
\hline & $\begin{array}{l}\text { Extreme } \\
\text { (5) }\end{array}$ & $\begin{array}{l}\text { Quite } \\
\text { (4) }\end{array}$ & $\begin{array}{l}\text { Moderate } \\
\text { (3) }\end{array}$ & $\begin{array}{l}\text { Slight } \\
\text { (2) }\end{array}$ & $\begin{array}{l}\text { Not at all } \\
\text { (1) }\end{array}$ & & \\
\hline Use of illness scripts $(n=89)$ & $14(15.7)$ & 34 (38.2) & $26(29.2)$ & $12(13.5)$ & $3(3.4)$ & $3.5(1.0)$ & $35(41.7)$ \\
\hline Heuristics $(n=89)$ & $9(10.1)$ & $32(36.0)$ & 37 (41.6) & $10(11.2)$ & $1(1.1)$ & $3.4(0.9)$ & $26(31)$ \\
\hline Estimation of pre-test probabilities $(n=89)$ & $22(24.7)$ & $36(40.4)$ & $21(23.6)$ & $9(10.1)$ & $1(1.1)$ & $3.8(1.0)$ & $46(54.8)$ \\
\hline Likelihood ratios $(n=89)$ & $8(9.0)$ & $28(31.5)$ & $35(39.3)$ & $16(18.0)$ & $2(2.2)$ & $3.2(0.9)$ & $41(48.8)$ \\
\hline Intuitive and analytical reasoning $(n=88)$ & $10(11.4)$ & $23(26.1)$ & 39 (44.3) & $15(17.0)$ & $1(1.1)$ & $3.3(0.9)$ & $14(16.7)$ \\
\hline Cognitive bias $(n=88)$ & $22(25.0)$ & $29(33.0)$ & $28(31.8)$ & $7(8.0)$ & $2(2.3)$ & $3.7(1.0)$ & $32(38.1)$ \\
\hline Thresholds $(n=88)$ & $22(25.0)$ & $33(37.5)$ & $25(28.4)$ & $6(6.8)$ & $2(2.3)$ & $3.8(1.0)$ & $38(45.2)$ \\
\hline Premature closure $(n=88)$ & $29(33.0)$ & $31(35.2)$ & $20(22.7)$ & $6(6.8)$ & $2(2.3)$ & $3.9(1.0)$ & $36(42.9)$ \\
\hline Formal decision analysis $(n=88)$ & $2(2.3)$ & $16(18.2)$ & $27(30.7)$ & $31(35.2)$ & $12(13.6)$ & $2.60(1.0)$ & $20(23.8)$ \\
\hline
\end{tabular}

*Bold font denotes mode

of clinical reasoning, which medical schools can use to guide their curricular design efforts.

Acknowledgements: The authors wish to thank the CDIM Survey and Scholarship Committee for their contributions to this manuscript.

Corresponding Author: Joseph Rencic, MD; Tufts Medical Center, Boston, MA, USA (e-mail:jrencic@tuftsmedicalcenter.org).

Author Contributions Dr. Rencic had full access to all of the data in the study, and takes responsibility for the integrity of the data and the accuracy of the data analysis.

\section{Funding None.}

\section{Compliance with Ethical Standards}

Ethical Approval The study was approved by the institutional review board at the Washington D.C. VA Medical Center in April 2015.

Conflict of Interest The authors declare that they have no conflict of interest.

\section{REFERENCES}

1. Kohn L, Corrigan J, Donaldson M. To err is human: Building a safer health system. National Academy of Science, Institute of Medicine; 2002.

2. Balogh EP, Miller BT, Ball JR. Improving diagnosis in health care. National Academies Press; 2016. http://www.nationalacademies.org/ hmd/ /media/Files/Report\%20Files/2015/Improving-Diagnosis/ DiagnosticError_ReportBrief.pdf. Accessed 6 Aug 2017.

3. Makary MA, Daniel M. Medical error-the third leading cause of death in the US. BMJ 2016;353:i2 139.

4. Leape LL, Berwick DM, Bates DW. What practices will most improve safety?: Evidence-based medicine meets patient safety. JAMA 2002;288(4):501-507.
5. Graber ML, Franklin N, Gordon R. Diagnostic error in internal medicine. Arch Intern Med 2005;165(13):1493-1499.

6. Singh H, Giardina TD, Meyer AN, Forjuoh SN, Reis MD, Thomas EJ. Types and origins of diagnostic errors in primary care settings. JAMA Intern Med 2013;173(6):418-425.

7. Nendaz MR, Raetzo MA, Junod AF, Vu NV. Teaching diagnostic skills: Clinical vignettes or chief complaints? Adv Health Sci Educ 2000;5(1):310.

8. Round A. Teaching clinical reasoning-a preliminary controlled study. Med Educ 1999;33(7):480-483.

9. Windish DM, Price EG, Clever SL, Magaziner JL, Thomas PA. Teaching medical students the important connection between communication and clinical reasoning. J Gen Intern Med 2005;20(12): 1108-1113.

10. Struyf E, Beullens J, Van Damme B, Janssen P, Jaspaert H. A new methodology for teaching clinical reasoning skills: Problem solving clinical seminars. Med Teach 2005;27(4):364-368.

11. Lee A, Joynt GM, Lee AK, et al. Using illness scripts to teach clinical reasoning skills to medical students. Fam Med 2010;42(4):255-261.

12. The Society to Improve Diagnosis in Medicine. Coalition for improved diagnosis. http://www.improvediagnosis.org/default.asp?page=CID. Accessed 6 Aug 2017.

13. Lucey CR. Medical education: Part of the problem and part of the solution. JAMA Intern Med 2013;173(17):1639-1643.

14. Lang VJ, Schuwirth L, Durning SJ, Rencic J. Assessment of clinical reasoning. In: Trowbridge Jr. RL, Rencic J, Durning SJ, eds. Teaching clinical reasoning. Philadelphia: American College of Physicians; 2015:117-154.

15. Gladwell M. Blink: The power of thinking without thinking. New York: Little, Brown and Company; 2007.

16. Kahneman D. Thinking, fast and slow. New York: Farrar, Straus, and Giroux; 2011.

17. Croskerry P, Petrie DA, Reilly JB, Tait G. Deciding about fast and slow decisions. Acad Med 2014;89(2):197-200.

18. Sherbino J, Norman GR. Reframing diagnostic error: Maybe it's content, and not process, that leads to error. Acad Emerg Med 2014;21(8):931933.

19. Monteiro SD, Sherbino J, Patel A, Mazzetti I, Norman GR, Howey E. Reflecting on diagnostic errors: Taking a second look is not enough. J Gen Intern Med 2015;30(9):1270-1274.

20. Ely JW, Graber ML, Croskerry P. Checklists to reduce diagnostic errors. Acad Med 2011;86(3):307-313.

21. Trowbridge RL, Rencic J, Durning SJ, eds. Teaching clinical reasoning. Philadelphia: American College of Physicians; 2015. 